\title{
Commentary
}

\section{Vulture conservation: the case for urgent action}

\author{
ROGER SAFFORD, JOVAN ANDEVSKI, ANDRE BOTHA, \\ CHRISTOPHER G. R. BOWDEN, NICOLA CROCKFORD, \\ REBECCA GARBETT, ANTONI MARGALIDA, IVÁN RAMÍREZ, \\ MOHAMMED SHOBRAK, JOSÉ TAVARES and NICK P. WILLIAMS
}

The collapse of vulture populations in South Asia 25 years ago, caused principally or entirely by veterinary use of the non-steroidal anti-inflammatory drug (NSAID) diclofenac is now well known (Oaks et al. 2004, Green et al. 2004). Some vulture populations in Europe have stabilized or increased thanks to conservation action, but anthropogenic threats persist. Vulture populations in other parts of the world, especially Africa, are now also endangered for other reasons.

Within the space of a few months in late 2017 and early 2018, four poisoning incidents resulted in the deaths of at least 387 vultures in Kenya, Tanzania, Zambia and Mozambique. Victims included at least four 'Critically Endangered' species, as well as mammals including lions Panthera leo. These followed many other similar tragedies, and such poisoning has been the main cause of a catastrophic decline in populations of formerly abundant African vultures. An observer visiting Africa's drylands in the 1970s would hardly have believed it possible that vultures could become so rare today.

In three of these instances, the poison was reportedly placed in retaliation for carnivore predation of livestock. Farmers who experience frequent crop-raiding by elephants, buffalo and other herbivores, and herders whose livestock fall prey to predators, occasionally resort to poisoning those animals in an effort to deal with the problem: an example of humanwildlife conflict (Ogada et al. 2012). Vultures, the unintended victims, consume either the poisoned baits or the carcasses of other animals that have died from poisoning. In the fourth, poachers had laced the carcass of a slain African elephant Loxodonta africana with large quantities of a toxic pesticide because circling vultures signal potential illicit activities to those who are combatting poaching: vultures are killed because they play the role of sentinels (Ogada et al. 2015). Some of the corpses, of both vultures and lions, were found to be missing body parts, suggesting a further motivation: the trade in body parts for belief-based use in misinformed attempts to treat a range of physical and mental diseases, or to bring good fortune (such use is sometimes referred to as traditional medicine, locally also as juju, muthi and fetish, although there is no evidence of any medicinal value.). Such practices have existed for many years, but with the rapid growth of human populations and more effective bird-killing methods using poisons the negative impacts on vultures (Buij et al. 2016) and other wildlife have grown.

Three distinct drivers were at work (human-wildlife conflict, ivory trade and belief-based use) but in each case the birds were killed by poison in the carcasses they found and consumed. Vultures are supremely adapted to scavenging but therefore equally vulnerable to threats tied to this behaviour, and severe population declines are expected even when poisoning incidents are infrequent (Monadjem et al. 2018, Murn and Botha 2018). These events form part of a wider 
trend: the mass poisoning of Africa's wildlife (Ogada 2014, Richards et al. 2017), which has resulted in what has been termed the African Vulture Crisis. Over 30 years, populations of eight vulture species in Africa have decreased by an average of $62 \%$ and seven were found to have declined at a rate of $80 \%$ or more over three generations (Ogada et al. 2016; see also Garbett et al. 2018a for a national example).

Following these events, the global conservation community is taking action, and in this article, we draw attention to the most recent and significant developments in vulture conservation, including the adoption by Governments across the range of African-Eurasian vultures of a Multispecies Action Plan for their conservation. We show that vulture conservation can work and urge for the implementation of the Action Plan in all its components to make this happen for all species across their ranges.

\section{Wider problems, and the value of vultures}

Outside Africa, three species of Gyps vulture endemic to South and South-East Asia began to decline in the mid-1990s at rates of up to $50 \%$ per year because of unintentional poisoning by veterinary use on cattle of the toxic NSAID diclofenac. The declines continued unchecked for about 15 years. One species, the White-rumped Vulture Gyps bengalensis, which was once the most abundant large raptor in the world, underwent a population decline of $99.9 \%$. Advocacy co-ordinated by the international coalition Saving Asia's Vultures from Extinction (SAVE) (Bowden 2017) led to bans on veterinary diclofenac and locally other NSAIDs shown to be toxic to vultures. SAVE is a partnership comprising in-range and international conservation NGOs, research institutes and government agencies and works closely with governments.

The removal of toxic NSAIDs from vulture habitats is challenging. Enforcement of bans is difficult and veterinary use of some toxic NSAIDs, such as aceclofenac and ketoprofen (Naidoo et al. 2010), remains unregulated in most range states. However, progress is being made. Diclofenac contamination of cattle carcasses in India has declined slowly but markedly since the statutory ban on its veterinary use in 2006 (Cuthbert et al. 2016) and vulture declines there have slowed or reversed (Prakash et al. 2019). The Indian (or Long-billed) Vulture Gyps indicus population in Pakistan has also partially recovered (Chaudhary et al. 2012). Much of Nepal is now apparently free from diclofenac and there are signs of vulture population recovery (C. Bowden pers. obs.). In Bangladesh, veterinary use of the toxic NSAID ketoprofen has now been banned from the areas of the country where vultures remain. Statutory bans on drug use have been found to be insufficient on their own. In situ conservation work focuses on creation of Vulture Safe Zones (VSZs) to complement national and international efforts for removing the veterinary NSAID threat through local communitybased advocacy. VSZs, which were conceived in South Asia, are large (Ioo-km radius) zones in which toxic NSAIDs are removed from the vulture food supply by targeted persuasion and education to allow recovery of wild populations and reintroduction of captive-bred birds. A wider application of the VSZ concept is described later.

The picture across the remainder of vultures' range is mixed, with declines in many areas but also some notable successes; these include progress in restoring vulture populations in parts of Europe. Despite conservation efforts, of 16 African-Eurasian ('Old World') vulture species, eight (four in each of Africa and Asia) are 'Critically Endangered', three 'Endangered' and three 'Near Threatened' (Table I). The Red List Index (Figure I) confirms the severity (relative to other birds) and timing (recent) of the deterioration in the conservation status of vultures.

Poisoning is the main threat to vultures in the majority of other regions too, such as the Balkans (Pantović and Andevski 2018), Spain (Margalida 2012) and Cambodia (Clements et al. 2012, Sum and Loveridge 2016, Loveridge et al. 2019), most often driven by human-wildlife conflict. Evidence for impacts on vultures from yet another poison - lead from hunting ammunition - is mounting 
Table 1. Species covered by the Vulture MsAP. Nomenclature and sequence follow del Hoyo et al. (2014); New World vultures and condors form a separate Order (Cathartiformes) and are not included here, as collectively their conservation status is far more favourable; however, they also suffer from poisoning and deserve further attention.

\begin{tabular}{lll}
\hline Species & Range & $\begin{array}{l}\text { Global Threat Level } \\
\text { (Red List category) }\end{array}$ \\
\hline Bearded Vulture Gypaetus barbatus & & $\mathrm{NT}$ \\
Egyptian Vulture Neophron percnopterus & Europe, Asia, Africa & EN \\
Red-headed Vulture Sarcogyps calvus & Europe, Asia, Africa & CR \\
White-headed Vulture Trigonoceps occipitalis & Asia & CR \\
Hooded Vulture Necrosyrtes monachus & Africa & CR \\
Himalayan Griffon Gyps himalayensis & Africa & NT \\
White-rumped Vulture Gyps bengalensis & Asia & CR \\
White-backed Vulture Gyps africanus & Asia & CR \\
Indian Vulture Gyps indicus & Africa, (Europe) ${ }^{2}$ & CR \\
Slender-billed Vulture Gyps tenuirostris & Asia & CR \\
Cape Vulture Gyps coprotheres & Asia & EN \\
Rüppell's Vulture Gyps rueppelli & Africa & CR \\
Griffon Vulture Gyps fulvus & Africa, (Europe) ${ }^{2}$ & LC \\
Cinereous Vulture Aegypius monachus & Europe, Asia, Africa & NT \\
Lappet-faced Vulture Torgos tracheliotos & Europe, Asia, (Africa) ${ }^{2}$ & EN \\
\hline
\end{tabular}

Notes:

${ }^{1} \mathrm{CR}=$ Critically Endangered; EN = Endangered; NT = Near Threatened; $\mathrm{LC}=$ Least Concern.

${ }^{2}$ Cinereous Vulture occurs in small numbers in N and W Africa; Rüppell's and White-backed Vultures similarly in Europe.

(Naidoo et al. 2017, Plaza and Lambertucci 2018); this has long been a known threat to condors in the New World. Hard evidence on whether lead exposure is contributing to vulture declines elsewhere is scarce and few studies have tested this; however, an association between hunting and elevated blood lead levels has been found in declining White-backed Vulture populations in Botswana (Garbett et al. 2018b), and there is mounting evidence that lead poisoning is a prevalent threat to vultures and raptors across Europe (for example, Berny et al. 2015, Carneiro et al. 2016, Ganz et al. 2018).

Other, non-poison threats exist. Collision and electrocution on energy infrastructure have killed large numbers of large birds including vultures, and this threat becomes more concerning if projected increases in energy installations, especially renewables, are not underpinned by sound bird-safe pole designs and correct siting (e.g. Carrete et al. 2012). Reduced food supply, habitat destruction and degradation, and human disturbance at colonies are further problems, of which the first two could be major factors, particularly in parts of Africa, but their precise impact has so far been difficult to ascertain.

Does it matter? The intrinsic value of vultures (as of all species) is, to many, reason enough to conserve them, but decision-makers may base decisions more on economic grounds. On this basis, the conservation case is still extremely strong, as vultures present an exceptionally clear example of birds providing a free ecosystem service, namely carrion consumption and related values stemming from this (Morales-Reyes et al.2017). Based on empirical studies and models, vulture declines are predicted to cause trophic cascades and disease outbreaks (Buechley and Şekercioğlu 2016). Studies have attempted to quantify certain financial benefits, reporting some high figures (Markandya et al. 2008) and vultures have other values too: they hold special place in cultures of many countries, including historically (e.g., as Nekhbet, a goddess in ancient Egyptian mythology), and have proven attractive to ecotourists. However, a comprehensive socio-economic and ecosystem service assessment has not been undertaken. 


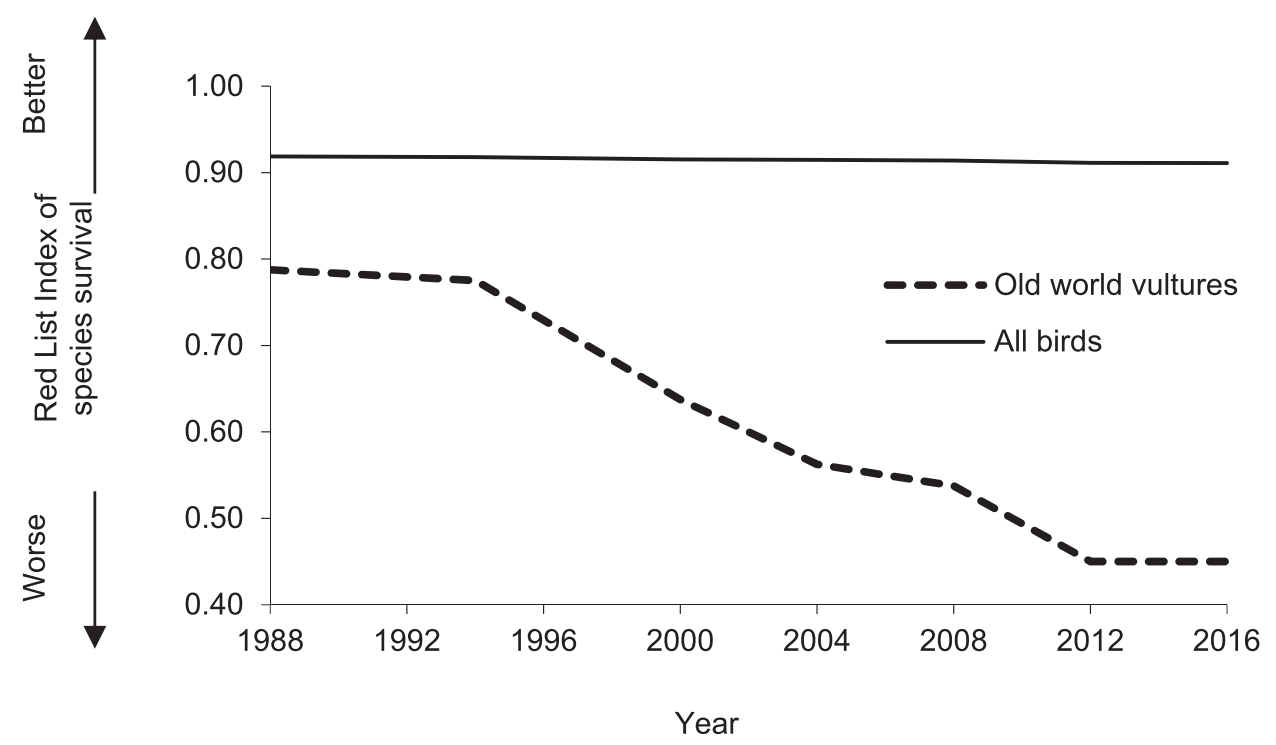

Figure 1. Red List Index for Old World vultures and for all birds, showing that vultures are both much more threatened than birds in general, and also declining at a significantly faster rate. A value of $I$ equates to all species being categorised as Least Concern and hence that none is expected to go extinct in the near future; a value of o would indicate that all species have gone extinct. Source: BirdLife International 2018a.

\section{Cause for hope: successful vulture conservation in Europe}

There have been at least local successes in all regions, but events in one continent show most clearly that vulture conservation can work on a large scale: in Europe, vultures are increasing in number and recolonising their old ranges. Although poisoning remains a problem even here (above), Griffon Vulture populations in Western Europe have increased by over $200 \%$ in the last 12 years (Spain alone holds over 26,00o pairs), while the continent's Cinereous Vulture population has increased by $50 \%$ in the last 20 years and the Bearded Vulture has been successfully reintroduced to parts of its former range, notably Andalucia, Spain. Despite the persistent poisoning threat, recovery is also beginning in the Balkans. These successes are attributed principally to tested and evidence-based conservation measures, strong legislation (in the form of the EU Birds and Habitats Directives) and significant funding available to implement solutions (with around $€ 80$ million invested in vulture conservation in the last 15 years).

Clearly, Europe is a reservoir of best practice that could be used elsewhere, although challenges remain, including the recent licensing of diclofenac for veterinary use in some countries; a complete ban on such use for livestock is needed in Europe to avoid such negative consequences to vulture populations as were experienced in South Asia (Margalida et al. 2014, Green et al. 2016).

\section{Concerted conservation action planning for vultures}

The threats to vultures are widespread, deep-rooted and severe, making them challenging to address even locally. But even successful site-scale conservation action is not enough, as the movements of vultures (revealed by satellite and GPS telemetry) have shown the vast movements they undertake. Accordingly, conservation action requires a broad approach and 
engagement of all Range States, including their Governments which are uniquely placed to enable the large-scale changes needed.

This realisation was the catalyst for international consensus on the need to develop a Multi-species Action Plan to Conserve African-Eurasian Vultures (Vulture MsAP) under an intergovernmental agreement: the Convention on the Conservation of Migratory Species of Wild Animals (CMS). The Coordinating Unit of the Memorandum of Understanding on the Conservation of Migratory Birds of Prey in Africa and Eurasia (Raptors MOU) facilitated the development of the Vulture MsAP, supported by its Technical Advisory Group and a Steering Group with representatives from the IUCN SSC Vulture Specialist Group, BirdLife International, Vulture Conservation Foundation and other specialists. Consultations with Range States, conservation specialists, species experts and other stakeholders, including a month-long public consultation over a complete draft, was a key part of the process, and the completed Vulture MsAP (Botha et al. 2017) was adopted at the 12th Conference of Parties to the CMS in October 2017.

The Vulture MsAP has three aims: (I) to rapidly halt current population declines in all 15 species covered by the Vulture MsAP, (2) to reverse recent population trends to bring the conservation status of each species back to a favourable level, and ( 3 ) to provide conservation management guidelines applicable to all Range States covered by the Vulture MsAP. It proposes 124 actions under 12 specific, mainly direct threat-reduction, objectives to achieve these aims; these actions cover research and monitoring, policy and legislation, education and awareness, and direct conservation action, requiring a concerted effort throughout its 12-year lifespan. The MsAP also identifies stakeholders in vulture conservation and policy opportunities, and mechanisms for international coordination of implementation.

In April 2018, an international meeting on vulture conservation as part of a wider Summit for the Flyways (BirdLife International 2018b) reinforced the importance of the Vulture MsAP and highlighted the need for a 'community of implementers' bringing together all stakeholders, for rapid response mechanisms for communities and governments to jointly tackle the threat of poison baits, and for safety testing for veterinary pharmaceuticals (including NSAIDs) to reduce this proven risk. VSZs were seen as a key part of the effort to conserve vultures in South Asia, and such landscape approaches show great promise in other regions, particularly Africa, although the threats as well as socio-economic and political contexts there are different, and so appropriate adaptation will be essential.

\section{Where next: planning, essential actions and 'flagship projects' to conserve vultures}

The scale of the conservation challenge is daunting; how can priorities be set and progress made? We see three main approaches. The first is to convert the MsAP into smaller-scale Action Plans focused on the most relevant actions for a given set of implementers, in the manner of national or regional multi-species plans which already cover various Asian countries. The MsAP endorses the 'blueprint' for the recovery of threatened vultures of South and South-East Asia developed and annually updated by the SAVE coalition (SAVE 2019); single-species plans at flyway or regional scale include the Flyway Action Plan for the Cinereous Vulture and the Eastern Mediterranean Flyway Action Plan for the Egyptian Vulture, both also adopted by CMS as a component of the Vulture MsAP. Second, the MsAP itself identifies a subset of 17 activities, whose immediate implementation is considered most important to ensure that progress towards achieving the goal is made as quickly as possible. Third, specific projects can make progress in their own right, but also build confidence and momentum in a wider programme; at the Summit for the Flyways (above) II such 'Flagship projects' were proposed to support implementation of the Vulture MsAP, by facilitating efforts across all range states, reducing critical threats, and conserving vultures along entire flyways as models for multi-country and -regional action for vultures. 
Vulture conservation is a major challenge. However, outstanding work has been and continues to be done to conserve these birds, with initiatives to address almost all of the threats and to restore populations. These include (to name only a few) integrated anti-poisoning campaigns in Africa and Europe, combining some or all of rapid response, law enforcement and mitigating human-wildlife conflict, while linking the plight of vultures to that of carnivores and elephants to form stronger conservation coalitions; reintroduction or restocking with captive-bred vultures, linked to reduction of the threat from veterinary NSAIDs, in South Asia, or reintroduction projects in Europe; and ever-increasing collaboration with the energy sector to reduce the threats of electrocution and collision. It is gratifying to recognise that two countries and one region very important for vultures-Greece, South Africa and the Balearic Islands-are already developing national vulture and/or raptor action plans in response to the MsAP, while Zimbabwe is completing its national plan started earlier.

However, such actions are just the beginning, and meanwhile the declines continue over large areas: in the most optimistic scenarios it seems likely that even to stabilise the decreasing populations across Africa, where the threats look most intractable, will take several years. To achieve this, a step change in conservation action is required, integrating vulture conservation into current and future development strategies, led by Governments and supported by all stakeholders, including many who have so far not recognised the importance of vultures. As vulture conservationists representing a range of concerned organisations, we commit our organisations to ensuring that all possible efforts to conserve vultures are made, and that the plight of these essential creatures continues to be broadcast to a global audience. We urge all those with the power to act for vultures to do so immediately.

\section{Acknowledgement}

The manuscript was improved by comments from R. E. Green and Louis Phipps.

\section{References}

Berny, P., Vilagines, L., Cugnasse, J.-M., Mastain, O., Chollet, J.-Y., Joncour, G. and Razin, M. (2015) VIGILANCE POISON: illegal poisoning and lead intoxication are the main factors affecting avian scavenger survival in the Pyrenees (France). Ecotoxicol. Environ. Safety 118: 71-82.

Botha, A. J., Andevski, J., Bowden, C. G. R., Gudka, M., Safford, R. J., Tavares, J. and Williams, N. P. (2017) Multi-species Action Plan to Conserve African-Eurasian Vultures. Abu Dhabi, United Arab Emirates: Coordinating Unit of the CMS Raptors MOU. (CMS Raptors MOU Technical Publication No. 5. CMS Technical Series No. 35).

Buechley, E. and Şekercioğlu, C. H. (2016) The avian scavenger crisis: Looming extinctions, trophic cascades, and loss of critical ecosystem functions. Biol. Conserv. 198: 220-228.

Buij, R., Nikolaus, G., Whytock, R., Ingram, D. J. and Ogada, D. (2016) Trade of threatened vultures and other raptors for fetish and bushmeat in West and Central Africa. Oryx 50: 606-616.

BirdLife International (2018a) State of the world's birds: taking the pulse of the planet. Cambridge, UK: BirdLife International.

BirdLife International (2018b) A Summit for the Flyways. April 23rd-26th 2018, Abu Dhabi, United Arab Emirates. Declaration and Outcomes. Cambridge, UK: BirdLife International.

Bowden, C. G. R. (2017) The creation of the SAVE consortium - Saving Asia's Vultures from Extinction: a possible model for Africa? Ostrich 88: 189-193.

Carneiro, M. A., Oliveira, P. A., Brandão, R., Francisco, O. N., Velarde, R., Lavín, S. and Colaço, B. (2016) Lead poisoning due to lead-pellet ingestion in Griffon Vultures (Gyps fulvus) From the Iberian Peninsula. J Avian Medicine and Surgery 30: 274-279.

Carrete, M., Sánchez-Zapata, J. A., Benítez, J. R., Lobónc, M., Montoya, F. and Donázar, J. A. 
(2012) Mortality at wind-farms is positively related to large-scale distribution and aggregation in griffon vultures. Biol. Conserv. 145: 102-108.

Chaudhary, A., Subedi, T. S., Giri, J. B., Baral, H. S., Bidari, B., Subedi, H., Chaudhary, B., Chaudhary, I., Paudel, K. and Cuthbert, R. J. (2012) Population trends of critically endangered Gyps vultures in the lowlands of Nepal. Bird Conserv. Internatn. 22: 1-9.

Clements, T., Gilbert, M., Rainey, H. J., Cuthbert, R., Eames, J. C., Bunnat, P., Teak, S., Chansocheat, S. and Setha, T. 2012. Vultures in Cambodia: population, threats and conservation. Bird Conserv. Internatn. 23: 7-24.

Cuthbert, R. J., Taggart, M. A., Mohini, S., Sharma, A., Das, A., Kulkarni, M. D., Deori, P., Ranade, S., Shringarpure, R. N., Galligan, T. H. and Green, R. E. 2016. Continuing mortality of vultures in India associated with illegal veterinary use of diclofenac and a potential threat from nimesulide. Oryx 50: 104-112.

Del Hoyo, J. and Collar, N., with Christie, D. A., Elliott, A. and Fishpool, L. (2014) HBW and BirdLife International illustrated checklist of the birds of the world. Volume 1. Nonpasserines. Barcelona, Spain: Lynx Edicions.

Ganz, K., Jenni, L., Madry, M. M., Kraemer, T., Jenny, H. and Jenny, D. (2018) Acute and chronic lead exposure in four avian scavenger species in Switzerland. Arch. Environ. Contam. Toxicol. 75: 566-575.

Garbett, R., Herremans, M., Maude, G., Reading, R. P. and Amar, A. (2018a) Raptor population trends in northern Botswana: a re-survey of road transects after 20 years. Biol. Conserv. 224: 87-99.

Garbett, R., Maude, G., Hancock, P., Kenny, D., Reading, R. and Amar, A. (2018b) Association between hunting and elevated blood lead levels in the critically endangered African white-backed vulture Gyps africanus. Sci. Total Environ. 630: 1654-166.

Green, R. E., Newton, I., Shultz, S., Cunningham, A. A., Gilbert, M., Pain, D. J. and Prakash, V. (2004) Diclofenac poisoning as a cause of vulture population declines across the Indian subcontinent. J. Appl. Ecol. 41: 793-800.
Green, R. E., Donázar, J. A., Sánchez-Zapata, J. A., and Margalida, A. (2016) Potential threat to Eurasian griffon vultures in Spain from veterinary use of the drug diclofenac. J. Appl. Ecol. 53: 993-1003.

Loveridge, R., Ryan, G. E., Sum, P., Grey-Read, O., Mahood, S. P., Mould, A., Harrison, S., Crouthers, R., Ko, S., Clements, T., Eames, J. C. and Pruvot, M. (2019) Poisoning causing the decline in South-East Asia's largest vulture population. Bird Conserv. Internatn. 29: 41-54.

Margalida, A. (2012) Baits, budget cuts: a deadly mix. Science 338(6104): 192.

Margalida, A., Boglinani, G., Bowden, C., Donázar, J. A., Genero, F., Gilbert, M., Karesh, W. B., Kock, R., Lubroth, J., Manteca, X., Naidoo, V., Neimanis, A., Sánchez-Zapata, J. A., Taggart, M. A., Vaarten, J., Yon, L., Kuiken, T. and Green, R. E. (2014) One health approach to the use of veterinary pharmaceuticals. Science 346 : 1296-1298.

Markandya, A., Taylor, T., Longo, A., Murty, M.N., Murty, S. and Dhavala, K. (2008) Counting the cost of vulture decline - an appraisal of the human health and other benefits of vultures in India. Ecol. Econ. 67: 194-204.

Monadjem, A., Kane, A., Botha, A., Kelly, C. and Murn, C. (2018) Spatially explicit poisoning risk affects survival rates of an obligate scavenger. Scientific Reports 8(4364).

Morales-Reyes, Z., Pérez-García, J.-M., Moleón, M., Botella, F., Carrete, M., Donázar, J. A., Cortés-Avizanda, A., Arrondo, E., Moreno-Opo, R., Jiménez, J., Margalida, A. and Sánchez-Zapata, J. A. (2017) Evaluation of the network of protection areas for the feeding of scavengers in Spain: from biodiversity conservation to greenhouse gas emission savings. J. Appl. Ecol. 54: 1120-1129.

Murn, C. and Botha, A. (2018) A clear and present danger: Impacts of poisoning on a vulture population and the effect of poison response activities. Oryx 52: 552-558.

Naidoo, V., Wolter, K., Cromarty, D., Diekmann, M., Duncan, N., Meharg, A. A., Taggart, M. A., Venter, L. and Cuthbert, R. 2010. Toxicity of non- steroidal antiinflammatory drugs to Gyps vultures: a new threat from ketoprofen. Biol. Lett. 6: 339-341. Naidoo, V., Wolter, K. and Botha, C. J. (2017) Lead ingestion as a potential contributing 
factor to the decline in vulture populations in southern Africa. Environ. Res. 152: 150-156.

Oaks, J. L., Gilbert, M., Virani, M.Z., Watson, R. T., Meteyer, C. U., Rideout, B. A., Shivaprasad, H. L., Ahmed, S., Chaudhry, M. J. I., Arshad, M., Mahmood, S., Ali, A. and Khan, A. A. (2004) Diclofenac residues as the cause of vulture population decline in Pakistan. Nature 427(6975): 630-633.

Ogada, D. L. (2014) The power of poison: pesticide poisoning of Africa's wildlife. Ann. New York Acad. Sci. 1322: 1-20.

Ogada, D. L., Keesing, F. and Virani, M. Z. (2012) Dropping dead: causes and consequences of vulture population declines worldwide. Ann New York Acad. Sci. 1249: 57-71.

Ogada, D., Botha, A. and Shaw, P. (2015) Ivory poachers and poison; drivers of Africa's declining vulture populations. Oryx 50: 593-596.

Ogada, D., Shaw, P., Beyers, R. L., Buij, R., Murn, C., Thiollay, J. M., Beale, C. M., Holdo, R. M., Pomeroy, D., Baker, N., Krüger, S. C., Botha, A., Virani, M. Z., Monadjem, A. and Sinclair, A. R. E. (2016) Another continental vulture crisis: Africa's vultures collapsing toward extinction. Conserv. Lett. 9: 89-97.
Pantović, U. and Andevski, J. (2018) Review of the problem of poison use and vulture poisoning in the Balkan Peninsula. Netherlands: Vulture Conservation Foundation.

Plaza, P. I. and Lambertucci, S. A. (2018) What do we know about lead contamination in wild vultures and condors? A review of decades of research. Sci. Total Environ. 654: 409-417.

Prakash, V., Galligan, T. H., Chakraborty, S. S., Dave, R., Kulkarni, M. D., Prakash, N., Shringarpure, R. N., Ranade, S. P. and Green, R. E. (2019) Recent changes in populations of Critically Endangered Gyps vultures in India. Bird Conserv. Internatn. 29: 55-70.

Richards, N., Ogada, D., Buij, R. and Botha, A. (2017) The killing fields: The use of pesticides and other contaminants to poison wildlife in Africa. Encyclopedia of the Anthropocene 1-8.

SAVE (Saving Asia's Vultures from Extinction) (2019) A Blueprint for the recovery of the threatened vultures of South and Southest Asia. Updated annually, downloaded from http://save-vultures.org/.

Sum, P. and Loveridge, R. (2016) Cambodia vulture action plan 2016-2025. Phnom Penh, Cambodia.

\section{ROGER SAFFORD*}

BirdLife International, The David Attenborough Building, Pembroke Street, Cambridge CB2 3 QZ, UK.

\section{JOVAN ANDEVSKI}

Vulture Conservation Foundation, Wuhrstrasse 12, CH-8003 Zürich, Switzerland.

ANDRE BOTHA

Endangered Wildlife Trust, Private Bag X11, Modderfontein, 1645, South Africa.

CHRISTOPHER G. R. BOWDEN, NICOLA CROCKFORD

Royal Society for the Protection of Birds, The Lodge, Sandy, Bedfordshire SG19 2DL, UK.

\section{REBECCA GARBETT}

BirdLife International, Volkers Garden, Terrace Close, Off Rhapta Road, Westlands, Nairobi, Kenya.

\section{ANTONI MARGALIDA}

Institute for Game and Wildlife Research, IREC (CSIC-UCLM-JCCM), 13005 Ciudad Real, Spain \& Division of Conservation Biology, Institute of Ecology and Evolution, University of Bern, Bern, Switzerland.

\section{IVÁN RAMÍREZ}

Stichting BirdLife Europe, Avenue de la Toison d'Or 67, 1060 Bruxelles, Belgium. 


\section{MOHAMMED SHOBRAK}

Biology Department, Faculty of Science, Taif University, PO Box 888, Taif, Kingdom of Saudi Arabia.

\section{JOSÉ TAVARES}

Vulture Conservation Foundation, Wuhrstrasse 12, CH-8003 Zürich, Switzerland.

\section{NICK P. WILLIAMS}

Memorandum of Understanding on the Conservation of Migratory Birds of Prey in Africa and Eurasia, Convention on Migratory Species Office - Abu Dhabi, United Nations Environment Programme, clo Environment Agency - Abu Dhabi, PO Box 45553, Abu Dhabi, United Arab Emirates.

*Author for correspondence; e-mail roger.safford@birdlife.org 